\title{
EL MARCO JURÍDICO-ADMINISTRATIVO DE LOS SERVICIOS SOCIALES DE LA COMUNIDAD AUTÓNOMA ANDALUZA
}

\author{
ALFREDO HIDALGO LAVIÉ \\ Doctor en Ciencias Políticas. \\ Profesor de Derecho Constitucional en la E.U.A. de Trabajo Social. \\ Jerez de la Frontera (Cádiz).
}

\section{INTRODUCCIÓN}

omo es sabido, en un período de tiempo muy breve, el Estado español ha experimentado una profunda e irreversible mutación tanto en sus estructuras administrativas y territoriales como en su fundamentación y desarrollo consiguiente normativo, no debiéndose olvidar, ni mucho menos, la muy extraordinaria interiorización de los valores y principios democráticos que nos permiten sostener con sólida convicción la expresión arriesgada y provocativa revolución de nuestra cultura política; o dicho de otro modo, la sustitución de un marco legal represivo y unas pautas de comportamiento coactivas por una irremediable seducción hacia una cultura pluralista sostenida no sólo sobre el respeto hacia la diversidad, sino, además, y principalmente, sobre un «gusto» enriquecedor de la heterogeneidad social, política y ética, en la línea del pensamiento de Alf Ross ${ }^{1}$.

Así pues, en poco menos de dos décadas, el Estado y la sociedad española se han modernizado, abandonando las orillas del Atlántico Sur para, simultáneamente, aproximarse al progresivo desarrollo democrático occidental. Numerosos son los ejemplos de esta transformación trascendental y rápida, pero dos de ellos, en mi opinión, ilustran perfectamente este cambio impresionante en el bienestar de los pueblos y de los ciudadanos que constituyen nuestro Estado: la creación del Estado de las Autonomías y la configuración de un sistema público de servicios sociales en aras de un bienestarismo político y social respectivamente, cuya materialización ha presupuesto, por un lado, una reordenación administrativa que ha conllevado no sólo a toda una serie de transferencias desde la administración central a las 
administraciones autonómicas, sino también a la necesaria creación de nuevas entidades (el Ministerio de Asuntos Sociales, consejerías autonómicas y concejalías municipales), así como a la elaboración y coordinación tanto de un Plan General Concertado como de un gran número de diversos planes puntuales con los que afrontar problemas, generales y específicos; y por otro lado, y en definitiva, el abandono de un sistema anacrónico basado en la beneficencia con reminiscencias de caridad religiosa. Ni qué decir tiene que estas transformaciones han sido, y siguen siendo, especialmente relevantes en áreas territoriales tradicionalmente atrasadas como la Comunidad Autónoma de Extremadura y la de Andalucía en donde los índices de producción económica y desempleo hablan por sí mismos.

\section{LA PROBLEMÁTICA DE LA LOCUCIÓN «SERVICIOS SOCIA- LES»}

A pesar del camino realizado, los servicios sociales siguen siendo una expresión poco afortunada en cuanto a su delimitación conceptual y su precisión terminológica. Su acepción genérica establece, gracias a su ambigüedad, un punto de intersección válido a todo tipo de interpretaciones, pero, como es sabido, rara vez las generalidades son útiles para menesteres más profundos y detallados.

En nuestro caso, parece bien fundada la afirmación respecto a las contradicciones que presenta el conjunto de los Estatutos de Autonomía, las cuales pueden ser un reflejo de la ausencia de una conciencia política madura de la protección social, muy en consonancia con la velocidad en la que se han realizado las transformaciones del proceso de modernización rápida anteriormente citadas ${ }^{2}$.

La diversidad de matices que cada profesional introduce en sus particulares definiciones de los servicios sociales, muestra claramente la problemática que encierra esta locución y el poco consenso existente al respecto, sin embargo, cada vez parece más apropiado el dicho de uso común «mucho ruido y pocas nueces» con el que afirmar que todos sabemos qué son los servicios sociales aunque para explicarlos cada uno utilice sus propios recursos para enfatizar más sobresalientemente algunos de los aspectos de su definición.

2 No obstante, y a pesar de la veracidad de esta realidad, también es cierto que la Ley de Servicios Sociales de Suecia de 1980, si seguimos considerando su modelo de welfare state como ejemplo universalmente paradigmático, tampoco contiene una definición de los servicios sociales, por lo que las interpretaciones de esta ausencia, en algunos casos, e insuficiencia, en otros, abren un abanico muy amplio de posibilidades muy diversas. Sobre este punto, ver Gloria Rubiol, Los servicios sociales II. Leyes de servicios sociales en Europa, Siglo XXI de España Editores, S.A., Madrid, 1986. 
Uno de los muchos inconvenientes por todos conocido es la ausencia de referencia explícita en nuestro Texto Constitucional ${ }^{3}$. Más aún, la Constitución de 1978 ni siquiera contiene reconocimiento alguno de un sistema público de servicios sociales, por lo que casi todo lo referente a la constitucionalización de los mismos está abierto a problemas diversos de interpretaciones.

Un ejemplo ilustrativo es el capítulo III del Título I, «De los principios rectores de la política social y económica», en donde tampoco, a pesar de ser el lugar idóneo dentro de la estructura orgánica del Texto Constitucional, se hace referencia alguna a los servicios sociales. Sin embargo, en él, así como en otros apartados específicos, todo es deducible, de tal modo que no se menciona a los servicios sociales, pero se habla de ellos, no se explícita claramente la obligación de los poderes públicos en su ejecución, pero sí se les compromete. Esta ausencia vs. insuficiencia ha merecido en nuestro país numerosas críticas, sin embargo, poco se ha reconocido que esta falta de intencionalidad del poder constituyente es común, dicho sea de paso, a casi todas las constituciones occidentales contemporáneas, considerada cualidad elogiable con la que no condicionar un modelo político-social determinado, abierto, por consiguiente, a la discusión y la acción políticas.

La cuestión es, pues, la siguiente: ¿estamos mejor sin una definición precisa de los servicios sociales en aras de la enriquecedora heterogeneidad?. Quizás, pero no por ello debemos no seguir esforzándonos en alcanzar un consenso suficiente sobre una realidad por todos conocida, ni mucho menos considerar a cada una de las definiciones, por el mero hecho de serlo, «digna» de consideración y referencia, por lo que estimo acertado que cuantos más elementos de naturaleza diversa contenga, más cerca estaremos de una delimitación conceptual compartida ${ }^{4}$.

En esta dirección es elogiable el último paso dado a este respecto por Jorge Garcés Ferrer al definir a los servicios sociales como «uno de los sistemas públicos de bienestar dentro de un Estado Social, que a través de la administración y de la sociedad, tienen la finalidad de

El art.50 de la C.E. es el único que menciona expresamente los servicios sociales.

4 Un claro ejemplo de esta diversidad de elementos corresponde a la escasa referencia realizada, entre el amplio número de definiciones de servicios sociales, sobre la financiación de estos y su modelo (elemento económico). Más frecuente es, no obstante, la utilización de su componente político, quién o quiénes promueven, desarrollan y gestionan los servicios sociales: ¿los poderes públicos?, ¿sólo la sociedad?, ¿ambos?, ¿en qué medida cada uno?. Por otro lado, a mayor especificidad más complejo resultan los detalles, por lo que, por ejemplo, de momento es patente la imposibilidad de incluir en la definición exclusivamente al Ministerio de Asuntos Sociales, ya que, como es sabido, otras actividades también relativas a los servicios sociales se encuentran en otros departamentos ministeriales, tales como las instituciones penitenciarias (Justicia). 
integrar y compensar a los ciudadanos y grupos desfavorecidos y de promocionar y universalizar el bienestar social $\aleph^{5}$. Un reciente y extraordinario enunciado conceptual que introduce a los Servicios Sociales como uno de los pilares sobre los que se sostiene la legitimidad del modelo de Estado contemporáneo, por más que, a mi modo de ver, la definición de Alemán Bracho sigue siendo el punto de referencia obligado para todo posterior intento de delimitación conceptual propuesta de los servicios sociales, «los servicios sociales son instrumentos de la política social (1), de los que disponen tanto la sociedad como los poderes públicos (2) para dar una respuesta válida a las necesidades de los individuos, grupos o comunidades (3) para la obtención de un mayor bienestar social y en definitiva para alcanzar una mayor calidad de vida $(4)^{6}$.

Una veloz endoscopia de esta definición nos permite apreciar la elogiable sistematización de preguntas y respuestas concatenadas: qué son (1), de quiénes (2), hacia quiénes (3), para qué (4). Sin embargo, sorprende, en mi opinión, que no se responda a una cuestión crucial sin cuya respuesta la existencia misma de los servicios sociales no tiene razón de ser: ¿por qué?.

Esto es, si se ha logrado con éxito delimitar en términos mínimos qué son los servicios sociales, cómo se hacen efectivos, de dónde proceden, a quiénes son dirigidos y para qué son utilizados, no se puede eludir de la definición a qué se debe su existencia, para qué se establecen o por qué es necesaria su aplicación. ¿No sería conveniente incluir el componente jurídico (prescripción constitucional) junto a los elementos constituyentes de la definición?. Si el bienestar es un derecho constitucionalizado, ¿no es esta misma constitucionalización el origen de la extensa expansión actual de los «enigmáticos» servicios sociales?.

Evidentemente, se podrá argüir sobre este punto la tan enunciada ambigüedad, ausencia e insuficiencia constitucional a la que yo mismo en estas líneas he hecho alusión, pero ninguna de estas realidades ciertas niegan la existencia de otra realidad análoga, y es, que por encima de las imprecisiones e insuficiencias que promueven multitud de lecturas, subyace un precepto constitucional implícito en lo que, comúnmente, es denominado el «espíritu» de la constitución, materializado en algunos apartados concretos de su articulado. Otra pregunta muy diferente, aunque, en gran medida, igualmente importante es la siguiente: admitido el precepto constitucional, el cual debe ser analizado, ¿cuál es el grado de compromiso extraído?.

5 Jorge Garcés Ferrer, Sistema político y administrativo de los senvicios sociales. Colección Políticas de bienestar social. Tirant lo blanch. Valencia, 1996, págs. 55 y 56.

* M.C. Alemán Bracho, El sistema puiblico de servicios sociales. Impredisur. Granada, 1991. 
Desde un enfoque estrictamente constitucional, es evidente que no es lo mismo un principio rector de la política social que un derecho fundamental, dado que el primero es sólo un mandato al legislador, o si se prefiere a los poderes públicos, mientras que el segundo sí es exigible en cuanto tal. Importante distinción que mide el grado de compromiso, entendiendo por éste, el alcance y la exigencia de responsabilidad, pero cuya medida, en absoluto, pone en entredicho, o cuestiona, su propia existencia, es decir, la responsabilidad del Estado en integrar a todos los ciudadanos en el bienestar social; de otro modo y en palabras de Sánchez Agesta, «la dignidad de las personas exige del Estado prestaciones positivas que hagan posible el ejercicio de esa libertad $\gg$. Una libertad que como todos sabemos no es efectiva si no se resuelven ciertas necesidades básicas, no en vano Demetrio Casado define, precisamente, a los servicios sociales como «actividades organizadas con objeto de satisfacer determinades necesidades humanas ${ }^{8}$.

En definitiva, considero que se podría dar un paso más hacia adelante en lo que concierne a una definición más completa y consensuada de los servicios sociales si en ella fuese incluido el componente jurídico indispensable con el que determinar la propia existencia del carácter público de los servicios sociales, de tal modo que junto a los elementos constituyentes de la noción fuese igualmente subrayado el origen constitucional de esta vía, cuyo objeto consiste en subsanar las desigualdades económicas y sociales de los ciudadanos y su finalidad última y encomiable, la consecución del bienestar colectivo.

\section{FUENTES JURÍDICAS PRIMARIAS DEL DESARROLLO NOR- MATIVO AUTONÓMICO ANDALUZ}

Necesariamente, todo enfoque jurídico de cualesquiera de las materias a tratar exige un tratamiento del marco constitucional como punto de referencia insustituible, no en vano, la Constitución es la norma suprema del ordenamiento jurídico y como tal el resto de la producción normativa debe ajustarse imprescindiblemente a los enunciados constitucionales ${ }^{9}$. Es por consiguiente lógico, aunque pueda parecer innecesario, que toda referencia al marco normativo de los servicios

7 L. Sánchez Agesta, Sistema político de la Constitución española de 1978. Editoriales de Derecho Reunidas. Madrid, 1991, pág. 101.

* Demetrio Casado. Introducción a los servicios sociales. Acebo. Madrid, 1991.

- Como se recordará, esta acepción jurídica de la Constitución representa toda una novedad introducida en el Texto de 1978, puesto que hasta la fecha la Constitución era entendida en su tradicional versión como pacto social en función de su exclusiva acepción política. 
sociales en la Comunidad Autónoma Andaluza debe remitirse a su norma jurídica superior.

Qué duda cabe que uno de los preceptos constitucionales fundamentales sobre el que se cimienta la existencia de los propios servicios sociales y sobre el que, generalmente, se sostiene la legalidad de la edificación del denominado Estado del Bienestar, corresponde al artículo 9.2, según el cual, son los poderes públicos los encargados de promover las condiciones necesarias para el desarrollo de la libertad y la igualdad entendida individual y colectivamente y facilitar la participación ciudadana en todos los niveles de la vida comunitaria.

Este artículo ha merecido siempre una especial importancia fundamentalmente por dos razones. La primera de ellas, porque la promoción a la que están obligados los poderes públicos constituye, sin duda alguna, un compromiso constitucional de primer grado con la justicia social, pero además porque «la acción de iniciar o adelantar una cosa procurando su logro» reclama necesariamente una postura activa y dinámica del sujeto que detenta los principales recursos humanos y materiales y, por ende, exige que para la consecución de esa «realidad efectiva», recogida en el artículo, resulte imprescindible una gran intervención pública, y en consecuencia, un sistema público de servicios sociales.

La segunda razón, y en estrecha consonancia con el popular art. 14, la igualdad de los individuos supera su tradicional acepción jurídica al adoptar la común dimensión moderna que la redefine como igualdad compensatoria para lo que es imprescindible, lógicamente, «remover los obstáculos que impidan o dificulten su plenitud».

Establecidos los cimientos del Estado intervencionista, su posterior procedimiento de actuación queda determinado por unos principios rectores de una política social y económica (Capítulo III, Título I), cuyas herrramientas -los servicios sociales-, aunque ni son definidos ni siquiera mencionados explícitamente, sí son recogidos y regulados indirectamente, diferenciando además, a pesar de la exhuberante reproducción terminológica, los servicios sociales generales de los servicios sociales específicos. Esta regulación diferenciada nos permite realizar el cuadro de la página siguiente que facilitará su ilustración.

Por último, junto a esta somera recapitulación de preceptos constitucionales relacionados estrechamente con los servicios sociales, es obvio que, aunque muy brevemente, es también necesario una mención a otro importante apartado, principalmente, debido a sus implicaciones con el ordenamiento jurídico. Me refiero, lógicamente, al art. 10.2 que integra los tratados y acuerdos internacionales que tras su ratificación se constituyen en una fuente jurídica primaria más. 


\begin{tabular}{|c|c|}
\hline Servicios Sociales Generales & Servicios Sociales Específicos \\
\hline $\begin{array}{l}\text { art.27. Educación } \\
\text { art.30.2. Objeción de conciencia } \\
\text { art.40. Política orientada al pleno empleo } \\
\text { art.43.1 y 2. Protección de la salud } \\
\text { art.43.3 Educación física, deporte y ocio } \\
\text { art.45. Medio Ambiente } \\
\text { art.47. Vivienda digna y adecuada } \\
\text { art.51. Protección consumidores y usuarios }\end{array}$ & $\begin{array}{l}\text { art.13.4. Asilados y apátridas } \\
\text { art.25. Reeducación y reinserción social } \\
\text { art.39. Protección de la familia } \\
\text { art.42. Protección del emigrante } \\
\text { art.48. Protección de la juventud } \\
\text { art.49. Protección de los disminuidos } \\
\text { físicos, sensoriales y psíquicos } \\
\text { art.50. Protección de la Tercera Edad }\end{array}$ \\
\hline
\end{tabular}

De este modo, y como ya es habitual, el paradigmático art. 25 de la Declaración Universal de los Derechos Humanos constituye el punto de referencia inicial por antonomasia, seguido por el Pacto Internacional de Derechos Económicos, Sociales y Culturales de 1966, en donde se establecen, principalmente, la protección de la familia (art.10), el derecho de toda persona y de su familia a un nivel de vida adecuado, especialmente a los aspectos referentes a la alimentación, vestido y vivienda (art.11), así como a la protección y desarrollo de su salud física y mental (art.12), y, por último, y fundamentalmente, la Carta Social Europea de 1961 en la que sí se mencionan explícitamente los servicios sociales en sus arts. 13 y 14 (ss.generales) y en sus posteriores artículos consagrados a las personas físicas o mentalmente disminuidas, protección de la familia, de la madre y del niño, protección de los trabajadores emigrantes y de sus familias, arts.15, 16, 17 y 19 respectivamente (ss. especializados). Constitución y normas internacionales constituyen, pues, la legislación básica de los servicios sociales sobre la que se asienta el posterior desarrollo de los mismos en el ámbito territorial de nuestra Comunidad Autónoma.

\section{EL MARCO JURÍDICO-INSTITUCIONAL PROPIO DE LOS SERVICIOS SOCIALES ANDALUCES}

Realizada esta primera aproximación de los servicios sociales, marco jurídico común, obviamente, para todas las comunidades autónomas que configuran el Estado de las Autonomías, la cual constituye la base (normas nacionales e internacionales) desde un punto de vista jerárquico de los servicios, debemos pues ahora adentrarnos en la normativa autonómica concreta, así como, fundamentalmente, en la Ley de Servicios Sociales que regula esta materia.

El Estatuto de Autonomía de Andalucía, muy en consonancia con los Estatutos de las otras comunidades autónomas, sólo permite a este 
respecto dos observaciones de carácter general, dado que en él sólo se realizan un par de referencias (arts. 12 y 13). Por un lado, y a modo de disposiciones generales del Titulo Preliminar, el Estatuto de Autonomía declara que propiciará la incorporación de la mujer en la vida laboral y social y promoverá la consecución del pleno empleo en el seno de la Comunidad con una actuación muy especial al sector de la población juvenil. Mientras que, por otro lado, el art. 13 del Título Primero es consagrado a la enumeración de las competencias exclusivas que corresponden a la Comunidad Autónoma, entre las cuales cabe destacar la asistencia y los servicios sociales tal y como es prescrito constitucionalmente en el art. 148.20 .

Qué duda cabe que ante este reducido número de piezas jurídicas, la Ley de Servicios Sociales de 1988, junto a los Decretos que proceden a desarrollarla, se convierte en el instrumento clave para la interpretación jurídica de los objetivos, naturaleza y tipos, así como otras tantas cuestiones, relacionadas con los servicios sociales en el seno de nuestra comunidad.

\subsection{Introducción a la Ley de Servicios Sociales de 1988}

Una primera característica, aunque de importancia menor, apreciada a simple vista en la Ley de SS. de 1988 corresponde a su contenido estructural de tipo intermedio, subdividido en 6 títulos, 33 artículos y 11 disposiciones ( 6 adicionales, 2 transitorias, 1 derogatoria y 2 finales). Como es sabido, el tamaño y estructura interna de una norma, al igual que sucede en las constituciones, invitan a realizar unas primeras observaciones que sugieren identificar la extensión de la misma con unos fines políticos precisos. De este modo, la brevedad es sinónimo de una mera declaración de intenciones y su opuesto una necesidad o intención normativa manifiesta en regular, incluso, aquellos aspectos menos comprometedores. Qué duda cabe, que en una Ley de estas características, cuya reproducción en otras áreas territoriales es muy similar, este rasgo, a pesar de ser el primero que llama la atención, es de una relevancia poco o nada considerable.

Más llamativo resulta, evidentemente, la definición que la Ley realiza de ella misma en su exposición de motivos, concretamente en su artículo primero. La comparación de su contenido con el artículo correspondiente en la Ley de SS. del País Vasco, que al ser la primera Ley sobre servicios sociales aprobada (Ley 6/1982, de 20 de mayo) habrá servido, sin duda, como referente inmediato a la posterior producción de las restantes normas, permite una aproximación nada desdeñable, respecto a la enumeración de sus objetivos, relacionada con la ausencia de la promoción de la participación de la persona en la 
vida ciudadana, pudiéndose entender su omisión como una no incompatibilidad manifiesta entre el desarrollo integral de la persona y su correspondiente participación en la vida comunitaria. Sin embargo, y a pesar de todas las elucubraciones posibles que pueden ser añadidas perfectamente a este respecto, lo cierto es que el legislador andaluz incorpora la participación del ciudadano y de sus grupos posteriormente, consagrando concretamente los capítulos II y III del Titulo IV.

De una curiosidad especialmente relevante es la distinción conceptual que diferencia los objetivos inmediatos y precisos de la Ley de su finalidad última, mucho más genérica, globalizadora e integral. Así pues, para la promoción del pleno desarrollo de los individuos, sus grupos y comunidades (finalidad), se establecen recursos, acciones y prestaciones tendentes a la prevención, tratamiento y eliminación de las causas que puedan conducir a su marginación (objetivos).

Finalmente, y a modo de curiosidad última, el legislador andaluz ha optado por los términos comunitarios y específicos para diferenciar los dos tradicionales modelos de servicios sociales entre el amplio abanico de locuciones por todos conocido.

\subsection{Los servicios sociales comunitarios y específicos}

Los ss. comunitarios son definidos tanto por sus áreas de actuación como por sus objetivos (arts. 6 y 8) y es por lo que la potenciación del desarrollo pleno de los individuos y de todos sus grupos convierten a los ss. comunitarios en la estructura básica del sistema público de servicios sociales. Para cumplimiento de estos fines, la Ley establece centros de prestación de estos servicios a cada una de las áreas de trabajo social y desde las cuales se ofrecen los servicios generales de: 1) información, valoración, orientación y asesoramiento a los titulares sobre sus derechos ${ }^{10}, 2$ ) impulso del asociacionismo con el fin de potenciar la vida comunitaria, 3) prestaciones de todo un conjunto de atenciones y cuidados de naturaleza doméstica, y 4) fomento de la convivencia y la reinserción social a fin de eliminar las barreras que obstaculizan la integración de los individuos.

Con la aprobación del Decreto 11/1992, de 28 de enero, que constituye una irremediable actualización de la primera medida adoptada en nuestra Comunidad en materia de ss. comunitarios con fecha de 5 de marzo de 1986, se ha procedido a combinar estas prestaciones anteriormente enunciadas estableciendo junto a los servicios de informa-

10 Según el art. 3 de la Ley de Servicios Sociales de 1988, la titularidad corresponde a los residentes en Andalucía, así como a los transeúntes, extranjeros, refugiados y apátridas establecidos en la Comunidad. 
ción (art.3), ayuda a domicilio (art.4), convivencia y reinserción social (art.5) y cooperación social (art.6), otras prestaciones de carácter económico, urgentes o coyunturales, de naturaleza complementaria, tales como las ayudas de emergencia social y las ayudas económicas familiares destinadas a paliar contingencias extraordinarias en el seno de unidades familiares (art.7.3 y 4), con especial atención en las segundas a las necesidades básicas de los menores. Asimismo, la aprobación en 1990 del Programa de Solidaridad de los Andaluces para la erradicación de la marginación y la desigualdad en Andalucía o el establecimiento de ayudas económicas complementarias de carácter extraordinario en favor de ancianos y enfermos incapacitados, beneficiarios de ayudas periódicas individualizadas y a favor de las personas con minusvalías, beneficiarios del subsidio de garantía de ingresos mínimos ", constituyen, igualmente, similares tomas de decisión de naturaleza económica encaminadas a paliar graves desigualdades socio-económicas que obstaculizan la plena integración de ciertos sectores sociales en el desarrollo óptimo de la vida comunitaria.

Resaltar, por último, sobre este punto, que el desarrollo normativo respecto a la creación y ordenación de las entidades y centros de servicios sociales en nuestra Comunidad fueron readaptados vía Decreto $161 / 1991$, de 30 de julio, con el fin de completar y modificar algunos aspectos de la regulación precedente, motivados en gran medida por la reestructuración de competencias exigida tras la creación en 1990 de la Consejería de Asuntos Sociales, en cuya única disposición final se faculta a su máximo responsable (Consejero/a de Asuntos Sociales) a dictar las normas necesarias para su desarrollo y ejecución.

En lo que concierne a los ss. especializados, es decir, aquellos que son ofertados a determinados sectores de la población que requieren una atención específica, tales como la familia, la juventud, los menores, la tercera edad, las minorías étnicas, los toxicómanos y, en definitiva, todo colectivo social que requiera una intervención social especializada, es preciso señalar que a pesar del menguado y único art.11 que la Ley dedica a este tipo de servicio social, se han venido aprobando desde 1990 toda una serie de normas que han permitido un desarrollo más expansivo de todas estas categorías. De este modo, destaca, por ejemplo, las medidas especiales adoptadas en materia de drogodependencias en $1994^{12}$, que han permitido una dedicación más

1 Decreto 400/1990, de 27 de noviembre y Decreto 477/1994, de 27 de diciembre respectivamente.

12 Decreto 68/1994, de 22 de marzo, si bien es preciso recordar que ya en 1988 se establecen centros y ss. especializados de atención a drogodependientes, siento estos servicios considerados como «aquelios que realizan actividades de acogida, orientación, desintoxicación, rehabilitación, reinserción o cualquier atra medida terapéutica tendente a mejorar su estado 
detenida para aquellas capas marginadas de la sociedad (andaluza) que, en palabras de Jorge Garcés Ferrer, «precisan para la resolución de sus necesidades una mayor especialización técnica que no es posible ofrecer desde los ss. generales $\rangle^{13}$. Así pues, estas medidas establecen mecanismos de prevención (información en centros docentes, campañas específicas, actividades de sensibilización social), asistencia (tratamiento en régimen de ambulatorio o internado, programas de mantenimiento y de prevención para evitar la transmisión de determinadas enfermedades) e inserción social (mediante intervenciones en el medio familiar y comunitario, desarrollo de programas formativos y ocupacionales y ampliación de la red de centros de día y pisos de reinserción), cuya naturaleza trasciende, como es sabido, el ámbito de actuación y la generalidad propia de los ss. comunitarios.

\subsection{Estructura político-administrativa de los servicios sociales an- daluces}

Paralelamente a la proyección expansiva de los servicios sociales (comunitarios y especializados) en la Comunidad Autónoma Andalu$\mathrm{za}$, la estructura político-administrativa, muy similar a lo acaecido a nivel estatal, se reproduce y se instaura en el marco normativo.

De este modo, se da paso en 1988 a la creación del Instituto Andaluz de Servicios Sociales (IASS), organismo autónomo de carácter administrativo, adscrito entonces a la Consejería de Salud y Servicios Sociales, para la gestión de los servicios sociales de la Junta de Andalucía, incluidos los transferidos de la Seguridad Social ${ }^{14}$. Asimismo, en 1989 se procedió a la creación del Instituto Andaluz de la Mujer, organismo autónomo con personalidad jurídica y recursos económicos propios, desde el cual promover la participación y la presencia de la mujer con el fin de superar toda discriminación laboral, cultural, económica o política de la misma ${ }^{15}$.

Un paso más en esta dirección se produce con la creación en 1989 y 1990 de los Consejos de Servicios Sociales en nuestra Comunidad, los cuales son constituidos como órganos regionales de carácter consultivo y asesor en los tres niveles de la administración autonómica,

físico, cológico o social, ya sea en forma ambulatoria o en régimen de internado», art. 2 del Decreto 330/1988, de 5 de diciembre.

13 J.G. Ferrer, Sistema Politico y Administrativo de los Servicios Sociales, ibid, pág. 191.

14 Las funciones, organización, régimen jurídico, financiación y recursos humanos del IASS se encuentran recogidos en el Decreto 252/1988, de 12 de junio, el cual experimentó dos años después una modificación puntual en la composición de su Consejo de Administración por medio del Decreto 173/1990, de 5 de junio.

15 Sobre este punto, consultar Decreto 1/1989, de 10 de enero. 
provincial y local, y cuyas funciones atañen a las actividades de información con carácter previo sobre los proyectos normativos de desarrollo de la Ley de Servicios Sociales, información sobre dotaciones presupuestarias de los servicios, evaluación de los resultados de la gestión de los mismos, emisión de dictámenes solicitados por las entidades competentes en la materia, colaboración en los programas y las campañas de información, divulgación y desarrollo de las actividades relacionadas con materias propias de servicios sociales, así como, y por último, promoción de la participación de los distintos sectores sociales en el desarrollo y potenciación de los servicios sociales ${ }^{16}$.

De una importancia mayor es, por el contrario, la creación de la Consejería de Asuntos Sociales en 1990 con la que asumir las competencias desempeñadas hasta entonces por la Dirección General de Servicios Sociales, la Dirección General de Juventud, la Dirección General de Emigración y el Comisionado de la Droga y desde la que adscribir a su área el Instituto Andaluz de Servicios Sociales, el Instituto Andaluz de la Mujer, el Consejo de Juventud de Andalucía y la Empresa Andaluza de Gestión de Instalaciones y Turismo Juvenil, dependiendo de esta Consejería asimismo la Comisión Interdepartamental de Emigración, el Comité Interdepartamental de la Juventud y el Consejo de Comunidades Andaluzas asentadas fuera del territorio de nuestra Comunidad. En definitiva, y como puede apreciarse, la nueva Consejería de Asuntos Sociales acabó absorbiendo las competencias que en su día asumían la Consejería de Salud y Servicios Sociales, la Consejería de Cultura y la Consejería de Presidencia.

Para su funcionamiento, además de la Viceconsejería y el Consejo de Dirección, integrado por los titulares de todos los órganos directivos y de los organismos autónomos adjuntos a la Consejería, su estructura orgánica fue desmantelada en las siguientes secretarías y direcciones generales:

- Secretaría General Técnica.

- Dirección General de Juventud.

- Dirección General de Política Migratoria.

- Dirección General de Atención al Niño.

- Comisionado para la Droga (con nivel orgánico de Dirección General).

Tres años más tarde, en 1993, se establece al fin, con el objeto de planificar y dirigir de forma más homogénea y coordinada la amplia gama de políticas relativas a los ss. comunitarios y racionalizar más

16 Aunque por razones de extensión no podemos detenernos en la estructura organizativa de estas entidades, sí es necesario, al menos, señalar la modificación experimentada en la composición del Pleno del Consejo Andaluz de Servicios Sociales registrada vía Decreto $172 /$ 1990 , de 5 de junio. 
eficazmente los recursos disponibles en la Consejería de Asuntos Sociales, la creación, en su seno, de la Dirección General de Acción Social, pudiéndose distinguir entre algunas de sus funciones importantes la coordinación de las actuaciones de seguimiento y evaluación del Plan de Servicios Sociales de Andalucía, la gestión de las políticas sociales correspondientes a la comunidad gitana y la coordinación de los Fondos y Programas, establecidos por las Comunidades Europeas, de la acción social comunitaria.

Sin embargo, un año después se abre paso una importantísima reestructuración en el seno del gobierno andaluz, cuya remodelación de consejerías conllevó a la constitución de la Consejería de Trabajo y Asuntos Sociales, la cual asumió, evidentemente, las competencias que hasta aquel entonces habían sido designadas a ambas consejerías por separado. De este modo, la nueva Consejería de Trabajo y Asuntos Sociales sumó a las competencias anteriormente enunciadas otras de naturaleza laboral, tales como el fomento, la promoción y la regulación de empleo, condiciones de trabajo, seguridad e higiene en el mismo, tiempo libre, etc.

Este cambio de denominación y de naturaleza ha exigido, lógicamente, una reactualización de su estructura orgánica con la que hacer frente a esta fusión de funciones y competencias, lo que ha significado el establecimiento de una Secretaría General de Asuntos Sociales y una Dirección General de Acción e Inserción Social que nos ha llegado hasta hoy ${ }^{17}$.

\subsection{El voluntariado social}

Una breve referencia es obligada a una de las formas de participación ciudadana más en auge actualmente. El voluntariado social, junto a los Consejos de Servicios Sociales, constituyen, como es sabido, un importante instrumento canalizador de la integración de las inquietudes sociales en aras no sólo del bienestarismo comunitario, sino además, y más importante incluso, de la profundización e interiorización de los ideales democráticos de la solidaridad y la cooperación, pilares elementales para una convivencia pacífica y enriquecdora. No en vano, nuestras normas jurídicas supremas (Constitución y Estatuto de Autonomía) recogen la obligación de los poderes públicos de facilitar la participación del ciudadano en todas las áreas de nuestra vida comuni-

17 Sobre las funciones que desempeña esta Dirección General así como toda la información referente a los cambios experimentados con la creación de la nueva Consejería de Trabajo y Asuntos Sociales, es de rigor consultar el Decreto 154/1994, de 10 de agosto, por el que se establece la nueva estructura orgánica de esta Consejería. 
taria. Como era pues obligado, la Ley de Servicios Sociales de Andalucía en su art.26 establece la obligación de regular reglamentariamente las funciones de estas personas que, y según la definición establecida por la Cruz Roja Española, «de una forma reflexiva, solidaria y desinteresada, desarrolla una actividad en beneficio de la Comunidad» ${ }^{18}$.

Ciertamente, y en mi opinión, no son gratuitas las interesantes reflexiones sobre esta realidad que suscita el artículo de $\mathrm{M}^{\mathrm{a}}$ del Carmen Andújar, muy especialmente, la referida, a modo de abierta interrogante, sobre «hasta qué punto las regulaciones normativas no están contribuyendo a que se convierta en legítima la forma de utilizar pseudoprofesionalmente a estas personas en situación de desempleo» ${ }^{19}$, pero, no obstante, no debe ser puesta en cuestión el elogiable esfuerzo del legislador en la protección normativa de la colaboración social con los órganos de Gobierno en la prestación de servicios sociales a través de las entidades propias del voluntariado. No en vano, la regulación del Estatuto del voluntariado y la creación de la Comisión del mismo (arts. 4 y 14 respectivamente del Decreto 45/1993, de 20 de abril) pueden y deben ser considerados un extraordinario desarrollo en la protección legal de una actividad, que, hasta la fecha, se encontraba desamparada.

\subsection{Competencias y Financiación Pública}

Ningún artículo de este tipo puede eludir, irremediablemente, dos aspectos centrales en materia de servicios sociales, sin los cuales, evidentemente, la materialización de los objetivos y su finalidad en esta Ley consagradas es absolutamente inviable: las competencias que corresponden a cada ente territorial y la imprescindible financiación pública para la gestión de los servicios sociales que hacen posible esta realidad.

Respecto a las primeras, algunas competencias a nivel autonómico han sido ya apuntadas al enumerar las funciones adjudicadas a la creación de la nueva Consejería de Asuntos Sociales (actualmente, Consejería de Trabajo y Asuntos Sociales como hemos visto), a las que habría que añadir otras, tales como la planificación general de los servicios sociales, coordinación de actuaciones y programas entre sus Española. Cuadernos de Acción Social, $\mathrm{n}^{\circ}$ 16. Ed. Ministerio de Asuntos Sociales. Enero/ Febrero, 1989.

19 $\mathrm{M}^{\mathrm{a}}$ del Carmen Andújar Tornero, Reflexiones sobre voluntariado. Rev. Trabajo Social Hoy, $n^{\circ}$ 8. Ed. Colegio Oficial de Diplomados en Trabajo Social y Asistentes Sociales. Madrid, 1995, pág.87. 
propios departamentos, asistencia y asesoramiento técnico a las entidades públicas o de iniciativa social que lo soliciten, realización de investigaciones y estudios sobre la problemática de los servicios sociales, supervisión y control del cumplimiento de la normativa en vigor, etc.

Las Diputaciones Provinciales, por su parte, asumen las competencias delegadas por la Junta de Andalucía, además de las que les estén, lógicamente, atribuidas legalmente como propias, entre las cuales cabe destacar especialmente la coordinación y gestión de los centros de ss. comunitarios, así como «de los centros de ss. especializados de ámbito local en los municipios de hasta 20.000 habitantes» (art. 18.2b. de la Ley de 1988), correspondiendo, por consiguiente, a las administraciones locales, de acuerdo con la Ley Reguladora de las Bases de Régimen Local, la gestión de los Centros de ss. comunitarios y especializados en municipios de más de 20.000 habitantes.

Finalmente, y en cuanto concierne a la financiación de estos servicios, y a pesar de que Andalucía parece ser la única Comunidad Autónoma que reparte equitativamente sus recursos económicos entre la administración autonómica y la administración local ${ }^{20}$, la Ley de Servicios Sociales andaluza no incorpora una medida normativa precisa que determine para estos servicios, como señala María Eugenia Zabarte, un cierto porcentaje presupuestario ${ }^{21}$, lo que impide, evidentemente, una asignación económica predeterminada que proporcione una continuidad estable de recursos por encima de las coyunturas políticas económicas desfavorables.

Así pues, del Título V de la Ley de Servicios Sociales de 1988 sólo puede ser destacado a este respecto, además de la colaboración financiera con la iniciativa social (art.29) y de la «posible» participación de los usuarios en los gastos de estos servicios (art.30), una única seguridad jurídica, sobre este último punto al menos, merecedora de elogio, que por su extraordinaria precisión impide, con su cobertura, la sustracción del ejercicio y disfrute de los mismos, puesto que, según el art.30.3, «ningún titular de derecho que carezca de recursos económicos quedará excluido de la prestación del servicio».

20) Ver cuadro de financiación en Normativa SS. de base, de Teresa Candil y otros. Rev. de servicios Sociales y Política Social, $\mathrm{n}^{\circ}$ 10. Consejo General de Colegios Oficiales de Diplomados en Trabajo Social y Asistentes Sociales. Madrid, 1989, pág. 99.

$21 \mathrm{M}^{\mathrm{a}}$, Eugenia Zabarte. Los Servicios Sociales como instrumentos de protección social: aspiraciones y logros legislativos. Rev. Documentación Social, $\mathrm{n}^{\circ}$ 79. Ed. Cáritas Española. Madrid, 1990, pág. 38. 


\section{VALORACIÓN FINAL}

Desde 1985, la implantación progresiva de los servicios sociales en la Comunidad Autónoma Andaluza ha recorrido un largo camino, no exento, ciertamente, de insuficiencias e imperfecciones. Pero una valoración global del mismo no permite unas conclusiones vagas y simples a menos que se quiera, con precipitación, faltar a la honradez del esfuerzo realizado.

Una reflexión pausada de los sucesivos acontecimientos acaecidos nos debe, y puede, invitarnos a unas afirmaciones concluyentes más optimistas.

Desde la creación de los primeros centros provinciales de toxicomanías en 1985, la creación de los ss. comunitarios en 1986, la organización del Instituto Andaluz de Servicios Sociales en 1988, la aprobación del Reglamento del Instituto Andaluz de la Mujer en 1989, sin olvidar la aprobación de la Ley de Servicios Sociales de 1988, y así sucesivamente hasta nuestros días, el legislador y el gobierno andaluz, en colaboración con las fuerzas sociales, han venido adoptando todo un conjunto de medidas encaminadas para hacer efectivo el popular precepto constitucional sobre la igualdad de todos los ciudadanos y ciudadanas. Los balances económicos realizados, sin embargo, nos muestran que nuestra realidad social es tan cruda como la percibimos, pero no es verdad que estemos tan alejados como al principio del modelo de bienestar que deseábamos. Honesto es, pues, reconocer que nuestra Comunidad Autónoma ha experimientado un óptimo desarrollo normativo e institucional de los servicios sociales por más que las graves insuficiencias actuales no permitan a los responsables públicos ni un sólo instante con el que desahogar el vigor del empeño aplicado.

\section{REFERENCIAS BIBLIOGRÁFICAS}

Legislación Básica sobre servicios sociales. Ed. Tecnos. Madrid, 1993.

ALEMÁN BRACHO, M.C.: El sistema público de servicios sociales. Impredisur. Granada, 1991.

CASARES, F.: Estudio comparado de las leyes autonómicas de servicios sociales. Actas de las Va Jornadas de Estudio del CEBS. Aplicación de las leyes de servicios sociales. Acebo. Madrid, 1987.

CABRA DE LUNA, M.A.: El sistema de los servicios sociales en el Estado Español. Cuadernos de Acción Social, n²0, octubre/diciembre. Madrid, 1985. 